\title{
CIRCULACIÓN DE INFORMACIÓN Y PROCESOS IDENTITARIOS. DECORACIÓN FACIAL EN ESTATUILLAS DEL CENTRO DE ARGENTINA
}

\author{
CIRCULATION OF INFORMATION AND REGIONAL IDENTITY PROCESSES. \\ FACIAL DESIGNS IN FIGURINES OF CENTRAL ARGENTINA
}

SEBASTIÁN PASTOR \& LUIS TISSERA ${ }^{B}$

Se desarrolla un análisis de los diseños de pinturas y/o tatuajes faciales, plasmados en un conjunto de figurinas de arcilla prehispánicas procedentes de la región centro de Argentina. Se examina la distribución del repertorio iconográfico en áreas discretas y, dentro de cada una, su capacidad de producir formas locales así como de regular los caudales de información puestos en circulación. Se propone un modelo en base a dos grandes esferas de interacción, definidas por el uso excluyente de segmentos del repertorio iconográfico y por lógicas contrastantes de funcionamiento, a partir de la generación de localismos y del grado de estandarización de la información transmitida.

Palabras clave: Arte mueble, Decoración facial, Comunicación visual, Esferas de interacción.

This paper presents an analysis of the designs of face paintings and/or tattoos in a set of pre-Hispanic clay figurines from central Argentina. It examines the distribution of the iconographic repertoire in discrete areas and, within each area, its capacity to produce local forms and to regulate the flow of circulating information. The interpretative framework supposes the use of facial decoration as a means of visual communication, with influence on the identity processes on both the personal and collective levels. A model is proposed based on two major spheres of interaction, defined by the exclusive use of segments of the iconographic repertoire and by contrasting functioning logics, based on the generation of localisms and the degree of standardization of the information transmitted.

Keywords: Portable art, Face decoration, Visual communication, Interaction spheres.

\section{INTRODUCCIÓN}

En el sector central de las Sierras de Córdoba y su piedemonte oriental (fig. 1), se desarrolló durante el Holoceno tardío final (ca. 1500-300 años AP) una tradición de elaboración de figurinas antropomorfas de arcilla. La misma integró un conjunto de innovaciones culturales que singularizaron a esta época, como la introducción de cultivos, la tecnología cerámica, la construcción de paisajes rupestres y, asimismo, la participación de numerosas comunidades locales en redes de interacción de alcance extra-regional (Berberián 1984, Medina et al. 2014, Pastor et al. 2012). Las figurinas son piezas pequeñas que miden entre 5 y $20 \mathrm{~cm}$ de largo, en posición erecta o extendida, o con menos frecuencia sentada (Outes 1911; Wyler-Castellanos 1924; Magnín 1937; Furt 1943; González 1943; Serrano 1944, 1945; Marcellino et al. 1967; Martín 1984; Berberián 1984, Bonofiglio 1985). Casi nunca se indican los brazos, ni ningún tipo de actitud corporal o facial: los ojos y la boca, por ejemplo, están siempre cerrados. En numerosos ejemplares se identifican rasgos que revelan su pertenencia al género femenino, como la presencia de senos y/o estado de embarazo (Pastor \& Tissera 2015) (fig. 2).

A Sebastián Pastor. Conicet, Centro de Investigación y Transferencia de Catamarca. Prado 366, (4700) San Fernando del Valle de Catamarca, Catamarca, Argentina. E-mail: pastorvcp@yahoo.com.ar

B Luis Tissera. Reserva Cultural Natural Cerro Colorado, Dirección de Patrimonio, Agencia Córdoba Cultura. Calle Pública s/n, (5821) Cerro Colorado, Córdoba, Argentina. E-mail: luistissera@gmail.com 


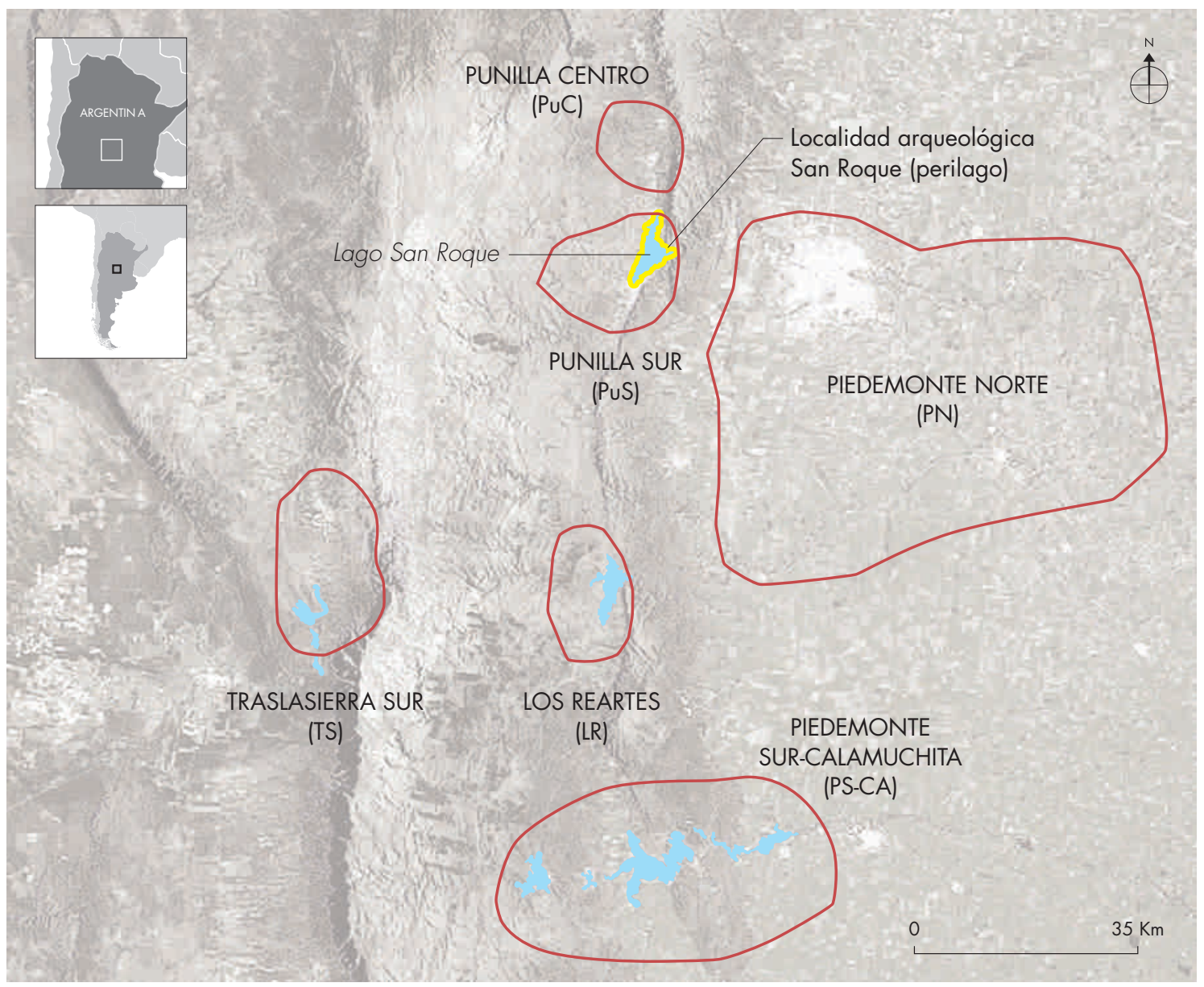

Figura 1. Distribución de las figurinas analizadas en el sector central de las Sierras de Córdoba y su piedemonte oriental. Figure 1. Distribution of the analysed figurines in the central area of the Córdoba Hills and their eastern piedmont.

Las piezas aparecen comúnmente rotas y mezcladas con variados residuos en los contextos domésticos. Según la hipótesis de trabajo, se trataría de objetos propiciatorios, portadores de potencias especiales capaces de favorecer necesidades como la reposición de la salud o la fertilidad. Otra alternativa, no necesariamente excluyente con la primera, es que se utilizaran como juguetes de niños. Es posible que, una vez acabados los rituales o actividades para los que se elaboraron, fueran abandonadas. Tales modalidades explicarían el modo de incorporación a los contextos arqueológicos, así como su elevada frecuencia, consistente con una elaboración y reposición continuas (Serrano 1944, Imbelloni 1950, Colazo 1970, González 1998, Miguez et al. 2014).

El conjunto de indicadores sugiere que se trata de representaciones de cuerpos femeninos, probablemente inertes y, sin dudas, de cuerpos culturalizados. Se señalaron las prendas y arreglos como delantales, cinturones, camisetas, collares, vinchas, gorros y peinados. También son comunes los diseños en el rostro, que representan tatuajes o pinturas. Sobre ellos se focaliza la presente investigación (fig. 3).

Por el momento se propone la marginación de posibles problemas o interrogantes, como el status de los sujetos representados (¿personas reales?, ¿seres mitológicos?), para centrarse en dos supuestos. El primero, que los diseños iconográficos en los rostros de las figurinas tienen una vinculación con prácticas concretas y tradiciones de decoración facial, vigentes en el campo sociocultural en estudio. El segundo, que alrededor de estos diseños y prácticas culturales se articulaba un canal comunicativo, con un caudal de información diferencialmente socializado. 

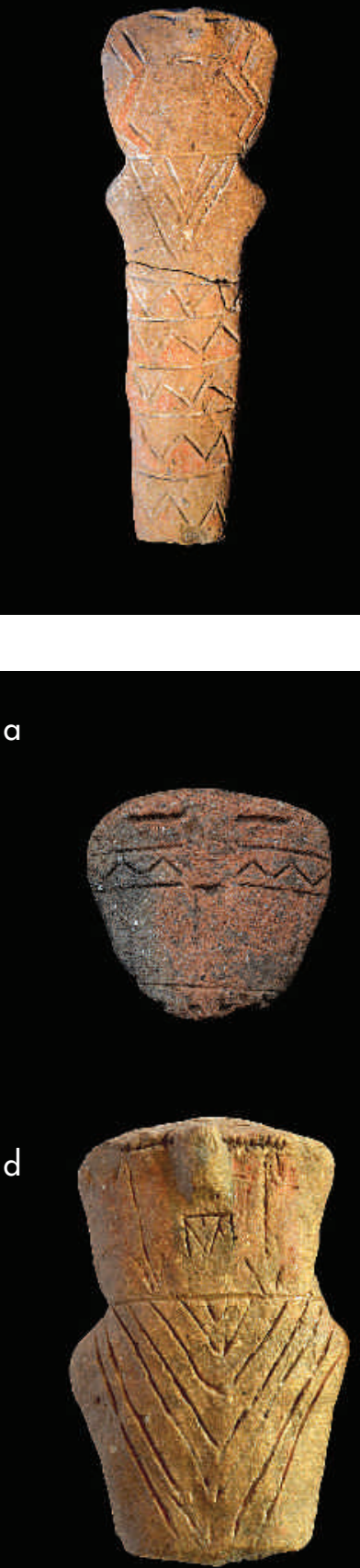

b

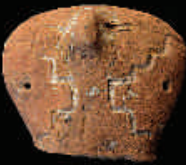

e

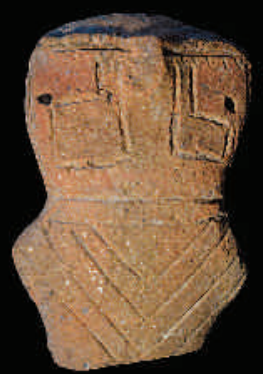

C

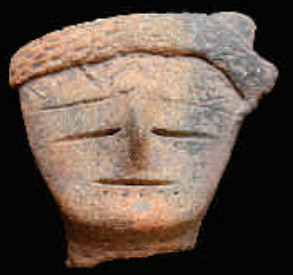

f

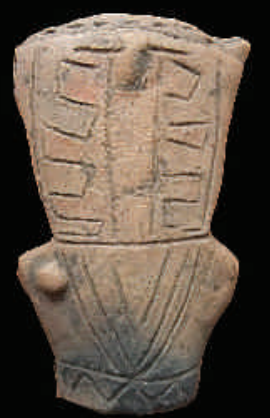

0

$5 \mathrm{~cm}$
Figura 2. Figurinas de arcilla. Procedencia: TS (izquierda); PS-CA (centro); PN (derecha). Figure 2. Clay figurines. Origin: TS (left); $P S-C A$ (center); PN (right).
Figura 3. Detalle de las decoraciones faciales. Procedencia: (a) PuS; (b) TS; (c) PS-CA; (d) PuS; (e) TS; (f) LR. Figure 3. Detail of the facial decorations. Origin: (a) PuS; (b) TS; (c) PS-CA; (d) PuS; (e) TS; (f) LR. 
En tal sentido interesa señalar que, al igual que las vestimentas, peinados y otros elementos de la ornamentación personal, las pinturas y tatuajes, ya sean faciales o corporales, desempeñaron un rol en la creación de subjetividades e identidades colectivas a diferentes niveles (Escobar 1993, Hansen 2004, Croucher 2010, Cifarelli \& Gawlinski 2017, Van Pool et al. 2017). En este trabajo se desarrolla un análisis basado en los diseños faciales de figurinas de arcilla, a partir de piezas publicadas y/o depositadas en colecciones museológicas, con diversas procedencias dentro de la región. Se busca un acceso arqueológico a las redes de interacción y canales comunicativos, que pueda complementarse con líneas como los diseños iconográficos de camisetas o delantales en las mismas figurinas u otras relacionadas con la circulación de códigos visuales y su influencia en la configuración del campo sociocultural (v.g. en otros objetos de arte mueble y a través del arte rupestre).

\section{ANTECEDENTES HISTÓRICOS Y ETNOGRÁFICOS}

Además de la representación de pinturas o tatuajes en diversos objetos arqueológicos de arte mueble (Cornely 1947-1949, Iribarren 1969, González 1998, Proulx 1999, Cichero 2016), o de la conservación directa de tatuajes en cuerpos momificados (Ubbelohde-Doering 1967, Allison et al. 1984, Arriaza 1988, Franco 2008), existe un considerable corpus de información histórica y etnográfica sobre este tipo de prácticas entre numerosos pueblos originarios de Sudamérica. Estos datos señalan la importancia de las imágenes plasmadas sobre el cuerpo como un medio de comunicación visual, vinculado a la construcción de identidades personales y colectivas.

Por ejemplo, entre los yámanas de Tierra del Fuego, los diseños eran muy variados, con una selección y disposición arbitraria de elementos, según el gusto y deseo momentáneo de quien aplicara la pintura. Esto no equivale a decir que dicha selección fuera errática o caprichosa: toda pintura tenía un significado especial. Es sugerente que un verbo que indicaba pintar la cara también tuviera otras acepciones relacionadas con la comunicación o los mensajes (Gusinde, en Orquera \& Piana 1999). Según diferentes observadores el rojo significaba amistad (Fitz-Roy 1839), amistad y alegría (Bridges 1885), alegría, alivio de luto, comunidad de bienes entre amigos (Martial 1888) o paz y alegría
(Lothrop 1928). El blanco indicaba guerra (Martial 1888), guerra o exhibición ceremonial (Lothrop 1928); en la preparación para el combate se agregaba blanco al rojo (Fitz-Roy 1839). Por su parte Gusinde dio a entender que los yekamushes (chamanes) tenían diseños propios de pinturas (en Orquera \& Piana 1999).

Pinturas y tatuajes, tanto faciales como corporales, transmitían información relativa al género, edad, status o identidad étnica de sus portadores. Entre los pilagás del Chaco argentino, los guerreros se pintaban el cuerpo con rayas blancas y negras para remarcar su condición de varones iniciados y así, diferenciarse de otros miembros y grupos de individuos (Idoyaga 2000). Entre los chamacocos o ishír del Chaco septentrional (Paraguay), la parafernalia del cazador incluía la realización de pinturas con impresiones palmares de color negro sobre una cobertura de ceniza gris, $o$ a la inversa, de un fondo negro con impresiones análogas en gris, a imitación de la piel del jaguar, para favorecer la captura de presas (Cordeu 1999).

También en la región chaqueña, en el caso de los mocovíes y abipones, los hombres se hacían tatuar

\begin{abstract}
tres rayas entre los ojos por sobre la nariz, dos debajo de cada ojo como también dos al lado del ojo izquierdo y derecho. Luego se hacen tatuar la barba inferior junto con el labio inferior a comenzar desde el interior del labio hasta debajo del mentón o hasta el comienzo de la garganta en derechura hacia abajo de manera que conforme a la anchura de la boca se ven una raya tras la otra de las cuales hay a veces de doce a quince (Paucke 2010 [1769]: 262).
\end{abstract}

En tanto que las mujeres exhibían
dos rayas paralelas desde arriba de la frente hasta la nariz [...] otras dos rayas paralelas sobre cada mejilla desde el ojo hasta por debajo del mentón. El labio inferior hasta debajo del mentón recibe incisiones en manera de rayas como en los hombres [...] sobre el labio superior debajo de la nariz se pungen cinco o seis triángulos que por afuera y por adentro están guarnecidos con puntitos y punciones. Luego se pasa por sobre la mejilla por ambos lados [...] Por sobre la frente tienen también su seña tatuada (Paucke 2010 [1769]: 262) (fig. 4).

En el caso de los tatuajes, el diseño total no se realizaba en una sola oportunidad, sino que era alcanzado en la adultez. El proceso comenzaba con la iniciación masculina o femenina y seguía durante el curso vital, indicando la maduración y desarrollo de la persona, a través de etapas o acontecimientos como el matrimonio, nacimiento de los hijos, establecimiento de la 


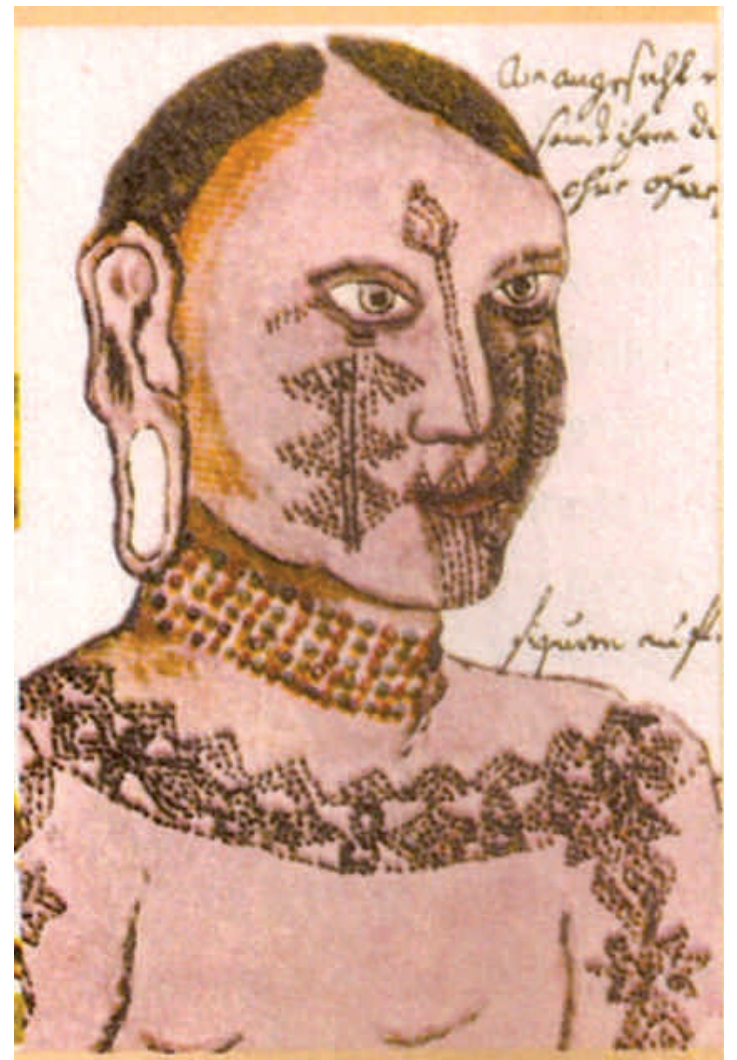

Figura 4. Tatuaje facial de una mujer mocoví o abipón (según Paucke 2010 [1769]). Figure 4. Face tattoo of a mocoví or abipón woman (according to Paucke 2010 [1769]).

vivienda propia o iniciación del primer hijo. Es decir, en ocasiones significativas para la vida del sujeto se agregaban nuevos motivos al tatuaje inicial. De este modo, la realización del tatuaje simbolizaba el proceso creciente de socialización y maduración del individuo (Idoyaga 2000). Estos diseños tenían, adicionalmente, un claro sentido de denotación de la identidad étnica:

Esa pintura $[\ldots]$ se hace para señalar que uno es Pilagá, es como el gobierno que da documento, o como se marcan los animales [...] Uno la ve y ya se sabe que es de la misma tribu, de la raza Pilagá [...] El Pilagá tiene la cara marcada y en la oreja tiene el agujero. Eso no tiene los otros, entonces uno sabe con quién tiene que pelear y quien es de la misma tribu. Al muchacho se lo marca porque así se sabe que es del grupo [...] Los Chulupí tienen otra pintura, los Tobas otras, así cada uno se reconoce. Si alguno viene de otra parte ya lo ve y sabe que es Pilagá (Idoyaga 2000).

Las fuentes etnográficas revelan, por un lado, la inconmensurable variedad de diseños, tanto pintados como tatuados, y por otro, la existencia de convenciones extendidas que permitían comprender los significados, aún compartidos entre diferentes pueblos y naciones a una escala macrorregional. Por ejemplo, el color negro era utilizado por diversos grupos para indicar luto. Según Paucke (2010 [1769]) los pampas, aucaes y puelches acostumbraban pintarse de negro toda la cara y andar así por algunos meses. Cerca del Río Segundo (Córdoba) se encontró con un grupo de pampas no cristianos:

\begin{abstract}
Nosotros oímos en una choza una voz llorosa a la que seguimos y encontramos que allí había fallecido una india. Bien pronto estuvo listo el luto que no lo había hecho ni un sastre ni un tejedor de crespones pues la madre de la difunta estaba sentada cerca del cadáver pintada tan de negro que creíamos que era una mora negra, pero fuimos informados que esto era el luto que se hacía por el duelo a los muertos (Paucke 2010 [1769]: 119).
\end{abstract}

En el noroccidente de la Patagonia, entre los pehuenches del siglo xIx, se aplicaba pintura facial realizada con "quelú o queilú (colorado), cuando los mocetones debían ir a la guerra. Con carú o cairú (negro), cuando se hallaban de duelo los parientes o bien asistían a un velatorio o concurrían al cortejo [...] De color blanco y de azul cuando se realizaban festines o asistían al rancho del nacimiento de un niño" (Rusconi 1961: 339). Según Métraux (1942), en un funeral entre los Guarayú del oriente boliviano, después de llenar la tumba de tierra todos los presentes saltaron sobre ella. Los dolientes se bañaron en una decocción de corteza de ibiraa (Peltophorumdubium), se pintaron de negro, cortaron sus cuerpos con un incisivo de agutí (Dasyprocta) y ayunaron. En el extremo sur del continente, entre los yámanas de Tierra del Fuego, también se utilizaba el negro para indicar luto. Sin embargo, según Gusinde (en Orquera \& Piana 1999), los colores no tenían un sentido único y unívoco. En el caso del luto se daba preferencia al negro, pero también se empleaban otros colores con la misma intención: la elección dependía en buena medida de las circunstancias. En una ceremonia realizada después del fallecimiento de una persona, los parientes más cercanos se pintaron únicamente de negro, pero los demás asistentes lo hicieron de forma muy variada. Además solía utilizarse el color negro para señalar otros significados, no solamente luto (Orquera \& Piana 1999).

En cuanto a los pueblos originarios de la serranía cordobesa, más allá de la arqueología, la única referencia 
que se conserva es del siglo XVI y corresponde a Diego Fernández, "El Palentino", quién señaló que, durante un encuentro bélico con los españoles "se juntó toda la tierra y viniendo en orden de guerra con gran pujanza de gente traían [...] las caras pintadas, la mitad negra y la mitad colorada" (Berberián 1987: 56). Esta descripción coincide notablemente con la ilustración realizada por Paucke (2010 [1769]) de un guerrero abipón o mocoví del siglo XviII con pintura facial (fig. 5).

\section{METODOLOGÍA}

Se registraron series de figurinas de arcilla de variadas procedencias, a partir de ejemplares publicados y/o depositados en colecciones museológicas. Con esta base se establecieron los repertorios iconográficos de diseños faciales desplegados en áreas discretas, definidas según criterios geográficos, ambientales y por la resolución de los datos referidos a los lugares de hallazgo. Además de la bibliografía (Outes 1911; Wyler-Castellanos 1924; Furt 1943; González 1943; Serrano 1944, 1945; Martín 1984; Bonofiglio 1985; Quetzal 2010) se documentaron ejemplares del Museo Arqueológico Numba Charava (Villa Carlos Paz), Museo Camín Cosquín (Cosquín), Museo Jesuítico Nacional (Jesús María), Museo Gunisacate (Las Peñas), Museo Antropológico Regional Camiare (Almafuerte), Museo Arqueológico Provincial Aníbal Montes (Río Segundo), Museo Arqueológico Municipal (Alta Gracia), Museo Regional Estrella de Piedra (Villa Rumipal), Museo Comechingón (Mina Clavero), Museo Rocsen (Nono) y colecciones particulares. De este modo, se identificaron los diseños faciales de 271 figurinas distribuidas en seis áreas: 1) norte del piedemonte oriental de las Sierras Chicas (PN, 22 ejemplares); 2) sur del piedemonte oriental de las Sierras Chicas/valle de Calamuchita (PS-CA, 40 ejemplares); 3) centro del valle de Punilla (PuC, 21 ejemplares); 4) sur del valle de Punilla (PuS, 111 ejemplares); 5) valle de Los Reartes (LR, 26 ejemplares); y 6) sur del valle de Traslasierra (TS, 51 ejemplares) (fig. 1).

Se consideraron los rostros completos o semicompletos, para los que eventualmente se asumió la simetría bilateral del diseño. Esta última característica domina ampliamente en la muestra, como se observa en más de un $90 \%$ de los ejemplares completos.

Nos interesan tres aspectos principales, relativos a la variabilidad y distribución de estos repertorios

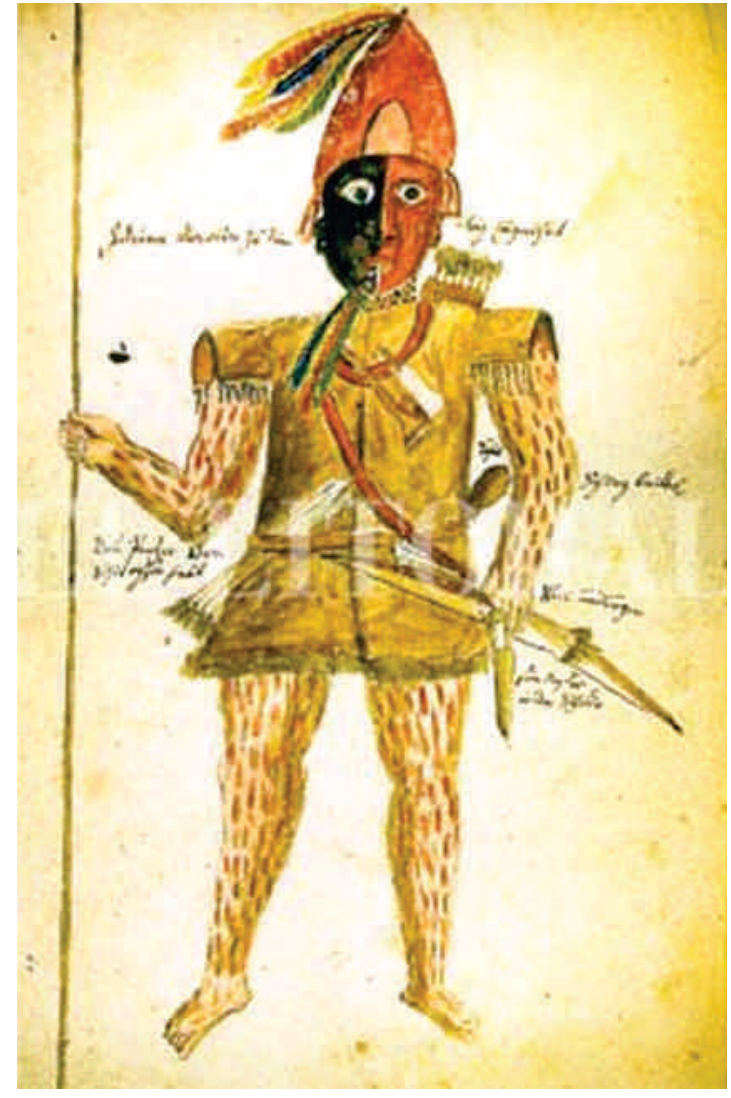

Figura 5. Guerrero mocoví o abipón con pintura facial (según Paucke 2010 [1769]). Figure 5. Mocoví or abipón warrior with face painting (according to Paucke 2010 [1769]).

iconográficos en la región. Por un lado, el grado de reserva local presente en cada lugar, según la cantidad de piezas con diseños exclusivos, no compartidos con otras áreas. Por otro lado, el grado de estandarización del repertorio, a partir de la cantidad de diseños diferentes sobre el total de piezas de cada área. En tercer lugar, las vinculaciones o grado de conectividad entre áreas, que permitan estimar flujos y vectores de circulación de información. Para ello se definieron grupos de diseños, según su afinidad morfológica, puesto que la mayoría de los casos corresponden a pequeñas variaciones de diferentes formas básicas En cuanto a los diseños presentes en dos o más áreas, se calculó la frecuencia de representación en cada una, como indicador cuali/ cuantitativo de la información compartida. 


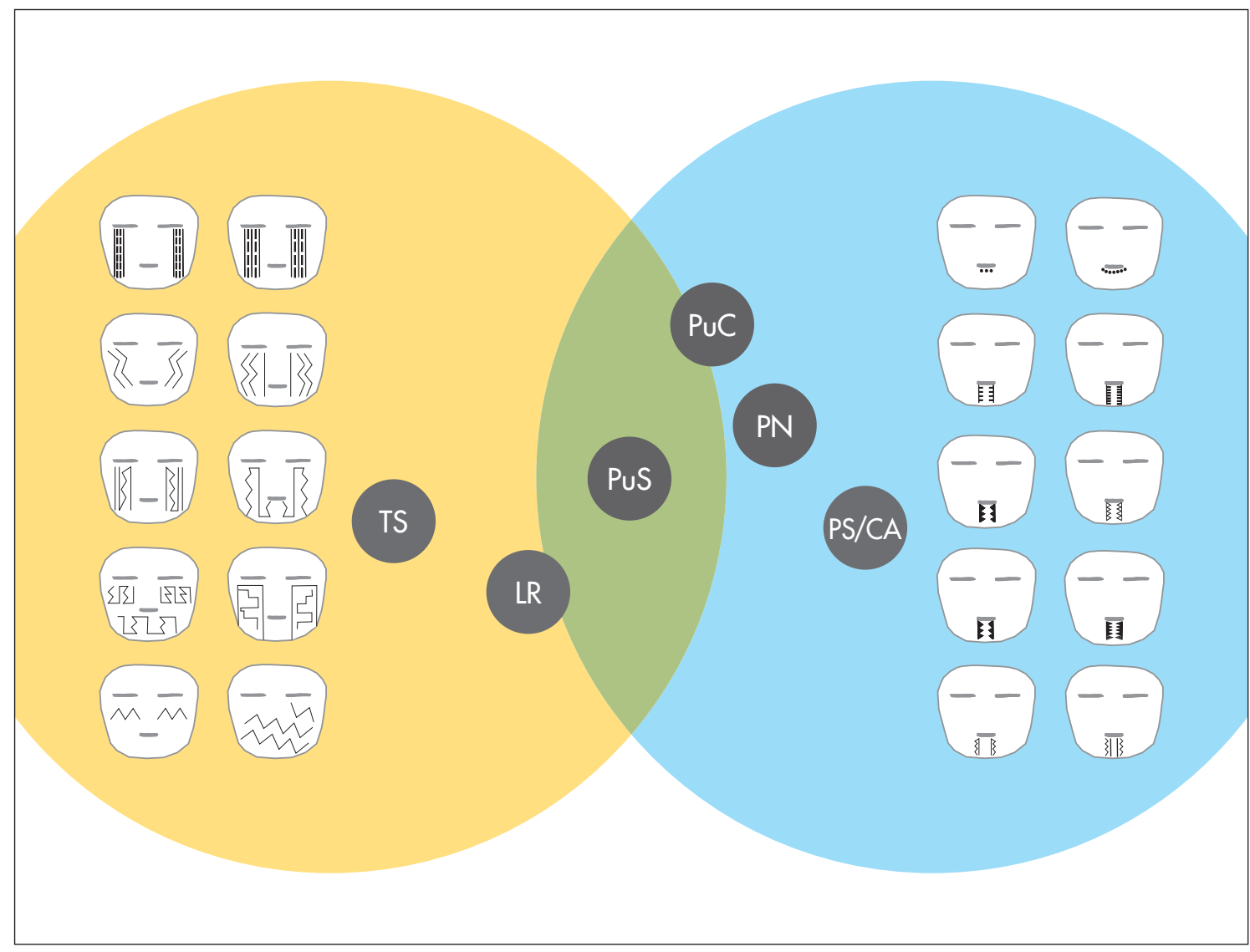

Figura 6. Esquema de esferas de interacción, en base a la decoración facial de las figurinas. Figure 6. Diagram of interaction spheres, based on the face decorations of the figurines.

\section{RESULTADOS}

El análisis de estos indicadores permite advertir aspectos particulares en la configuración de cada área, así como sus articulaciones en una red de mayor proyección geográfica. A partir de los resultados obtenidos se propone un modelo interpretativo que define dos grandes esferas de interacción, en base a sus repertorios iconográficos y a lógicas de funcionamiento contrastantes, con sectores de mutua exclusión y asimismo, con espacios de interpenetración. Las diferentes áreas ocupan posiciones relativas dentro de este esquema, ya sea en el centro o en los márgenes de cada esfera, o bien en el espacio de interpenetración (fig. 6).

Una de las esferas tiene una proyección oriental, dentro del ámbito geográfico considerado, y se caracteriza por: 1) diseños del grupo A (A02-A06, A10-A25; puntos y líneas ubicados debajo de la boca; fig. 7); 2) un bajo índice de reserva local; y 3 ) una alta estandarización del repertorio, en la posición central, junto a una menor estandarización o regulación de los caudales iconográficos en las posiciones marginales (tablas 1 y 2).

El área PS-CA ocupa el centro de esta esfera, mientras que $\mathrm{PN}$ y $\mathrm{PuC}$ se ubican en sus márgenes, próximas al espacio de interpenetración con la segunda esfera (fig. 6).

Esta última tiene una proyección occidental y se define por: 1) diseños de los grupos C (C05-C14; líneas continuas, cortadas y puntos con disposición vertical), $\mathrm{D}$ (D01-D17, líneas en zig-zag con disposición vertical), E (E01-E23, líneas escalonadas) y H (H01-H05, H07-H26, líneas en zig-zag con disposición horizontal), todos ellos ubicados entre los ojos, las mejillas y eventualmente sobre o debajo de la boca (figs. 8-11); 2) un alto índice de reserva local; y 3 ) una mínima estandarización del repertorio iconográfico (tablas 1 y 2). El área TS ocupa 


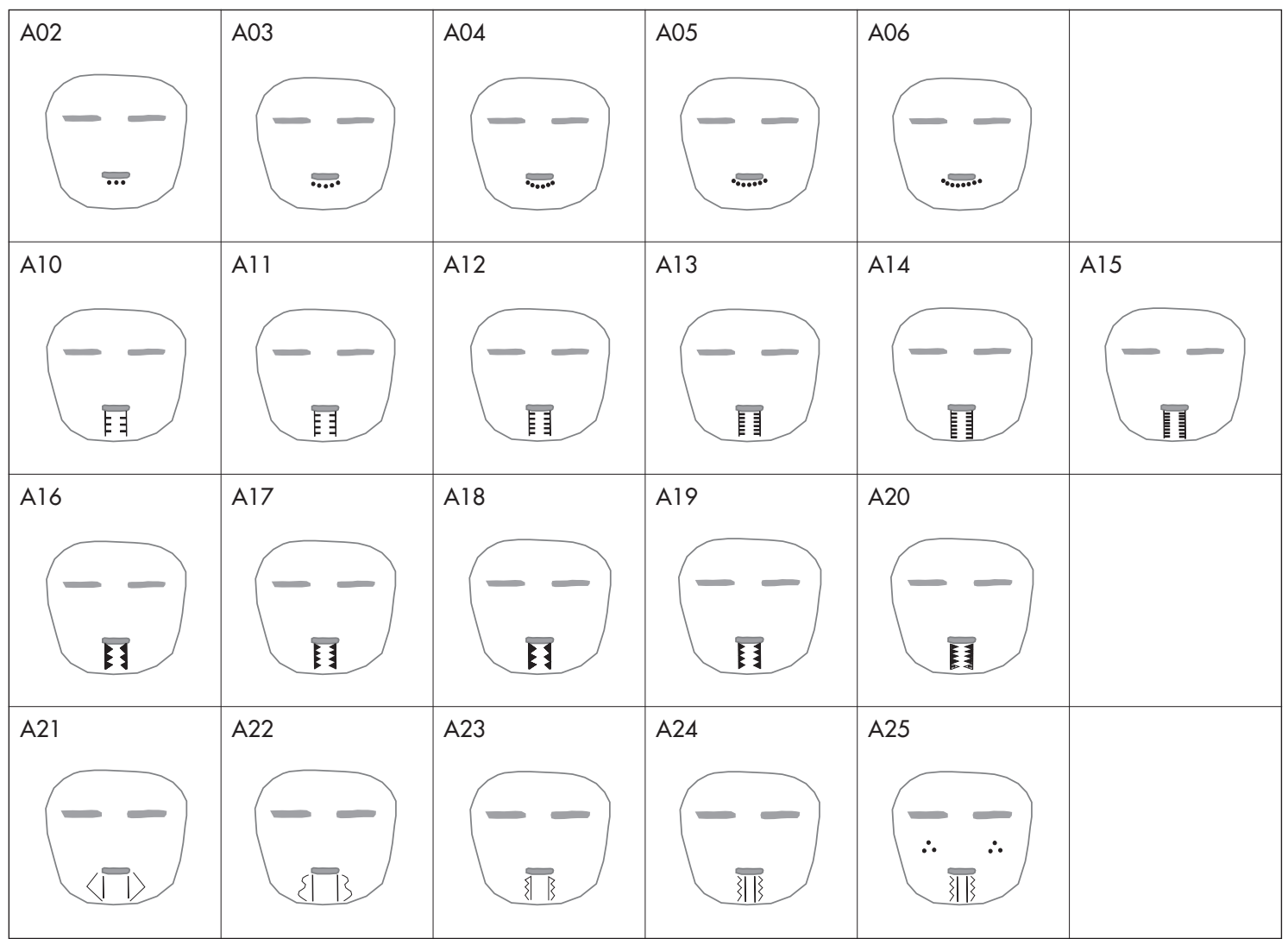

Figura 7. Diseños faciales del grupo A (esfera oriental). Figure 7. Facial designs of group A (eastern sphere).

Tabla 1. Distribución de los diseños faciales en las áreas analizadas (gris claro: esfera oriental; gris oscuro: esfera occidental). Table 1. Distribution of facial designs in the analysed areas (light gray: eastern sphere; dark gray: western sphere).

\begin{tabular}{|c|c|c|c|c|c|c|}
\hline & $\begin{array}{l}\text { PIED. SUR / } \\
\text { CALAMUCHITA } \\
\text { (PS-CA) }\end{array}$ & $\begin{array}{l}\text { PIED. NORTE } \\
(\mathrm{PN})\end{array}$ & $\begin{array}{c}\text { PUNILLA } \\
\text { CENTRO } \\
(\mathrm{PuC})\end{array}$ & $\begin{array}{l}\text { PUNILLA SUR } \\
(\mathrm{PuS})\end{array}$ & $\begin{array}{c}\text { LOS REARTES } \\
\text { (LR) }\end{array}$ & $\begin{array}{l}\text { TRASLASIERRA } \\
\text { (TS) }\end{array}$ \\
\hline A02-A06 & $11(27,5 \%)$ & $2(9,1 \%)$ & - & $9 \quad(8,1 \%)$ & $2(7,7 \%)$ & - \\
\hline A10-A 15 & $12 \quad(30 \%)$ & $4(18,2 \%)$ & $2(9,5 \%)$ & $8 \quad(7,2 \%)$ & - & $(2 \%)$ \\
\hline A16-A20 & $4 \quad(10 \%)$ & $2(9,1 \%)$ & - & $2(1,8 \%)$ & - & - \\
\hline A21-A25 & $5(12,5 \%)$ & $1(4,5 \%)$ & - & - & $2(7,7 \%)$ & - \\
\hline A07-A09 & - & $1(4,5 \%)$ & $1(4,8 \%)$ & $12(10,8 \%)$ & - & $1 \quad(2 \%)$ \\
\hline B01-B05 & - & $2(9,1 \%)$ & $1 \quad(4,8 \%)$ & $5(4,5 \%)$ & - & $5 \quad(9,8 \%)$ \\
\hline B06-B11 & - & $1(4,5 \%)$ & $1(4,8 \%)$ & $3(2,7 \%)$ & $2(7,7 \%)$ & $2(3,9 \%)$ \\
\hline $\mathrm{C} 02-\mathrm{C} 04$ & - & $1(4,5 \%)$ & $1(4,8 \%)$ & - & - & $1 \quad(2 \%)$ \\
\hline G01-G19* & $5(12,5 \%)$ & $3(13,6 \%)$ & $3(14,3 \%)$ & $12(10,8 \%)$ & $2(7,7 \%)$ & $1 \quad(2 \%)$ \\
\hline A26-A29 & - & - & $6(28,6 \%)$ & $1 \quad(0,9 \%)$ & - & - \\
\hline
\end{tabular}




\begin{tabular}{c|c|c|c|c|c|c} 
& $\begin{array}{c}\text { PIED. SUR } \\
\text { CALAMUCHITA } \\
(\text { PS-CA })\end{array}$ & $\begin{array}{c}\text { PIED. NORTE } \\
(\text { PN })\end{array}$ & $\begin{array}{c}\text { PUNILLA } \\
\text { CENTRO } \\
(\text { PUC })\end{array}$ & $\begin{array}{c}\text { PUNILLA SUR } \\
(\text { PUS })\end{array}$ & $\begin{array}{c}\text { LOS REARTES } \\
(\text { LR })\end{array}$ & $\begin{array}{c}\text { TRASLASIERRA } \\
(\text { TS })\end{array}$ \\
B12-B14 & $1(2,5 \%)$ & - & - & $2(1,8 \%)$ & - & - \\
\hline F05-F09 & - & - & - & $1(0,9 \%)$ & - & $4(7,8 \%)$ \\
\hline F10-F14 & - & - & - & $5(4,5 \%)$ & $1(3,8 \%)$ & - \\
\hline C05-C14 & - & - & $1(4,8 \%)$ & $9(8,1 \%)$ & $3(11,5 \%)$ & $1 \quad(2 \%)$ \\
\hline D01-D17 & - & $1(4,5 \%)$ & - & $14(12,6 \%)$ & $1(3,8 \%)$ & $7(13,7 \%)$ \\
\hline E01-E23 & - & $1(4,5 \%)$ & - & $6(5,4 \%)$ & $9(34,6 \%)$ & $7(13,7 \%)$ \\
\hline H01-H26 & - & $1(4,5 \%)$ & $2(9,5 \%)$ & $13(11,7 \%)$ & $3(11,5 \%)$ & $12(23,5 \%)$
\end{tabular}

el centro de esta esfera, mientras que LR se ubica en una posición marginal, cercana al espacio de interpenetración (fig. 6).

Por su parte, el área PuS se localiza dentro de este espacio de interpenetración, a través de una configuración que la vincula parcialmente con ambas esferas: 1) aquí confluyen los componentes iconográficos distintivos de cada esfera; 2) presenta un alto índice de reserva local, afín al panorama de la esfera occidental; y 3 ) se aprecia una tendencia a la estandarización o regulación de los caudales de diseños, en sintonía con el área PS-CA (en el centro de la esfera oriental) (fig. 6, tablas 1 y 2).

Más allá de este esquema, se advierten componentes del repertorio iconográfico con una distribución amplia o generalizada entre las diferentes áreas, que contribuyeron de algún modo a la integración de la totalidad del espacio regional: grupos A (A07-A09, líneas verticales debajo de la boca); B (B01-B11, líneas verticales y quebradas debajo de los ojos y eventualmente sobre las mejillas); C (C02-C04, líneas verticales entre los ojos y mejillas, pintadas de rojo) y G (G01-G19), excepto G12 y G16, líneas y puntos entre los ojos y mejillas, con disposición horizontal) (figs. 12-13).

Otros diseños se encuentran en la situación opuesta, restringidos en su circulación a espacios acotados. Estos últimos se relacionan especialmente con áreas con un alto índice de reserva local y una baja estandarización del repertorio, en función de su capacidad de producir variabilidad y localismos (C16-C17, líneas verticales que delimitan campos rellenos con líneas oblicuas; F01-F04, F15-F16, líneas escalonadas entre los ojos y mejillas; G12 y G16, líneas horizontales sobre las mejillas y debajo de la boca; H06, línea doble en $\mathrm{V}$
Tabla 2. Reserva local y estandarización del repertorio iconográfico en las áreas analizadas. Table 2. Local reserve and standardization of the iconographic repertoire in the analysed areas.

\begin{tabular}{c|c|c} 
ÁREA & $\begin{array}{c}\text { ÍNDICE DE } \\
\text { RESERVA LOCAL }\end{array}$ & $\begin{array}{c}\text { ÍNDICE DE } \\
\text { ESTANDARIZACIÓN }\end{array}$ \\
\hline $\begin{array}{c}\text { Piedemonte-llanura } \\
\text { Sur/ Calamuchita }\end{array}$ & 0,52 & 0,56 \\
\hline $\begin{array}{c}\text { Piedemonte-llanura } \\
\text { Norte }\end{array}$ & 0,45 & 0,87 \\
\hline Centro de Punilla & 0,59 & 0,81 \\
\hline Sur de Punilla & 0,70 & 0,68 \\
\hline Los Reartes & 0,67 & 1,00 \\
\hline Traslasierra Sur & 0,81 & 0,94
\end{tabular}

sobre el rostro, una continua y otra punteada; grupos I, cruciformes; J, formas de flecha, rastros de ave; y K, cuadrúpedos sobre las mejillas; fig. 14).

Por último, se señala la presencia de diseños particulares, con una distribución acotada solo a dos áreas, que sugieren su participación en la creación de vínculos específicos, cuya proyección no alcanza la escala de las dos esferas regionales definidas. En estos casos se advierte el rol articulador del área PuS: diseños A26-A29, escalonados debajo de la boca (en la vinculación entre PuS y $\mathrm{PuC}$ ); B12-B14, líneas dobles en ángulo recto u obtuso sobre las mejillas (vínculo entre PuS y PS-CA); F05-F09, formas escalonadas (vínculo entre PuS y TS) y F10-F14, formas escalonadas (vínculo entre PuS y LR) (fig. 15). 


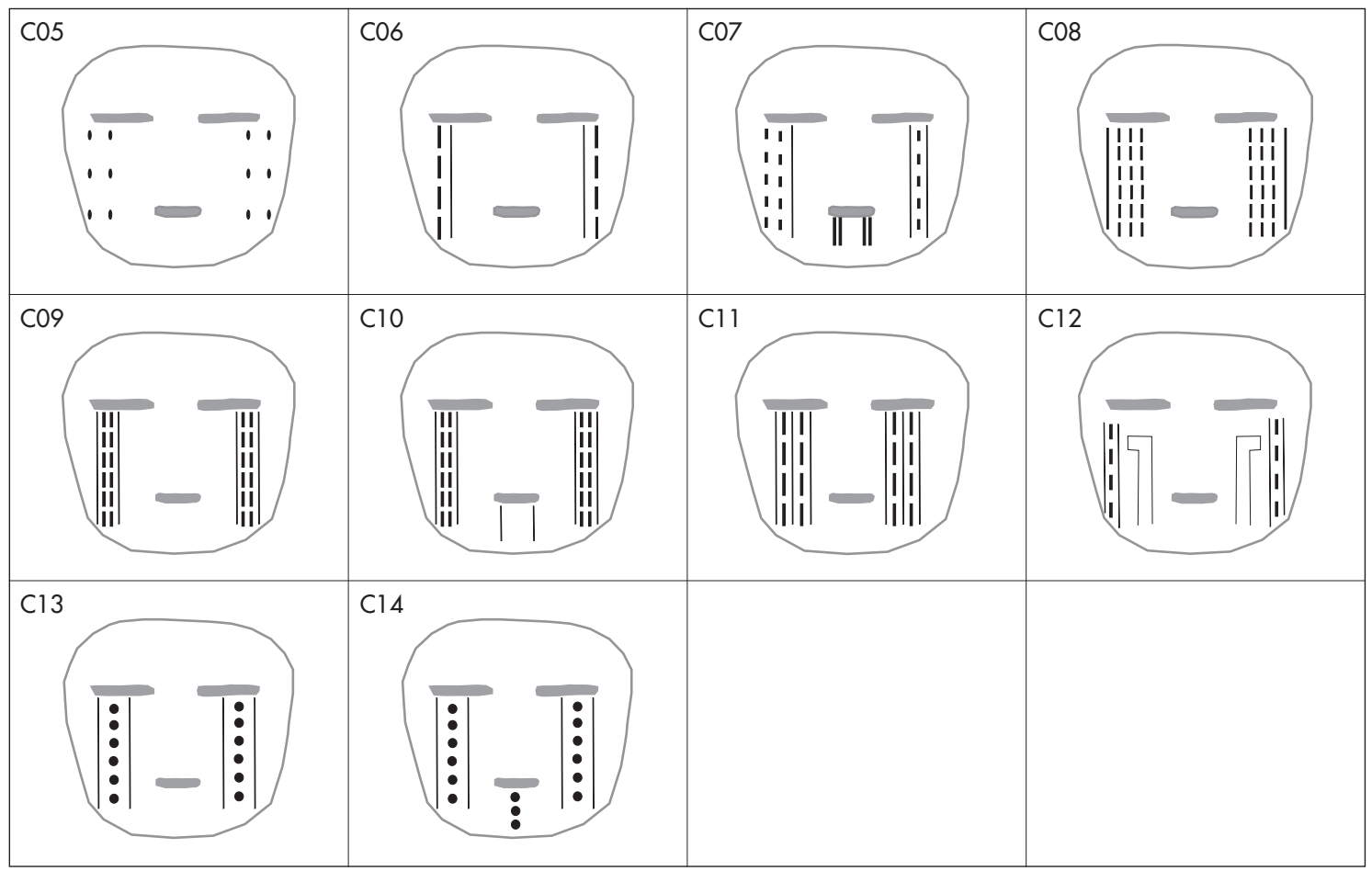

Figura 8. Diseños faciales del grupo C (esfera occidental). Figure 8. Facial designs of group C (western sphere).

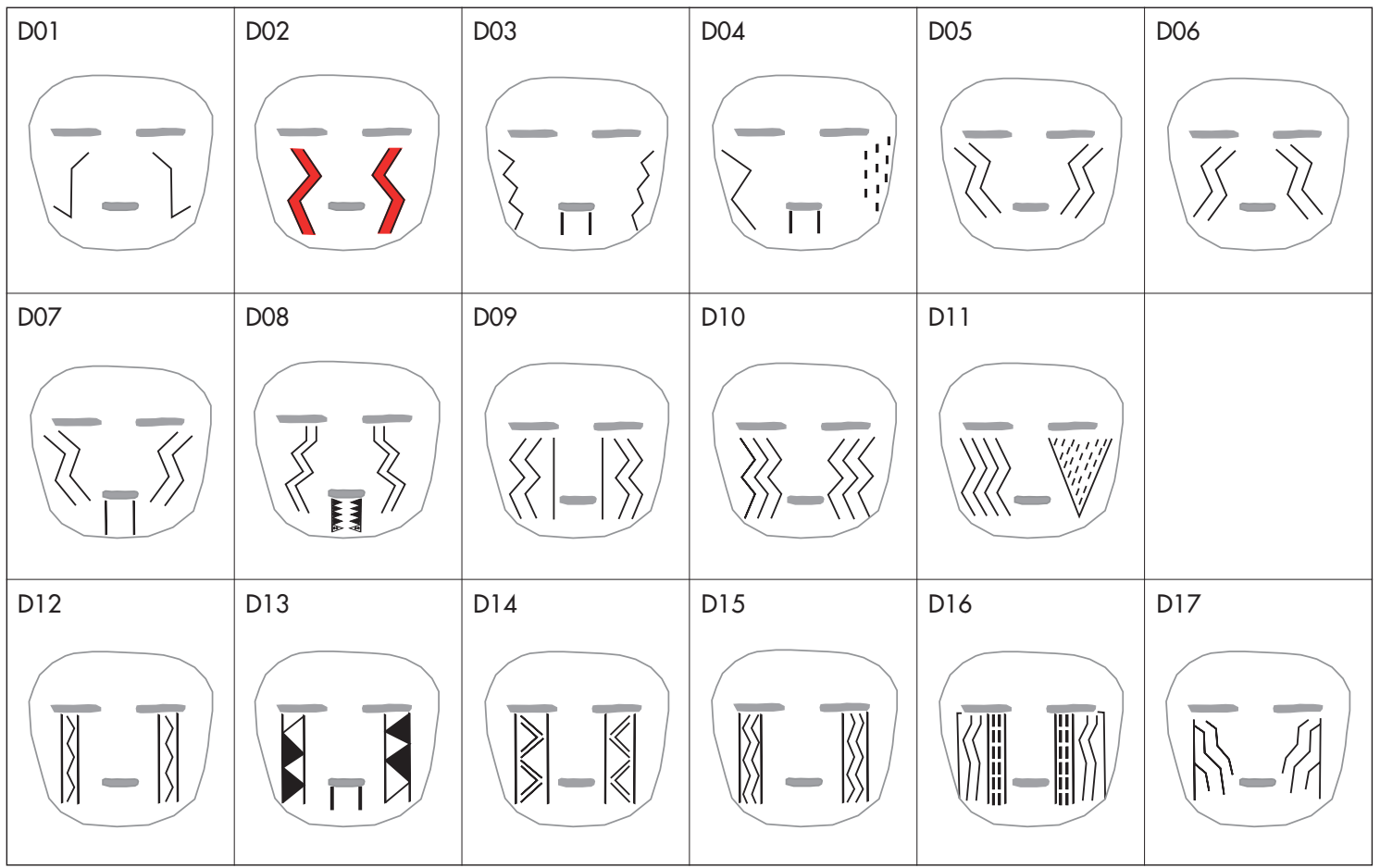

Figura 9. Diseños faciales del grupo D (esfera occidental). Figure 9. Facial designs of group D (western sphere). 


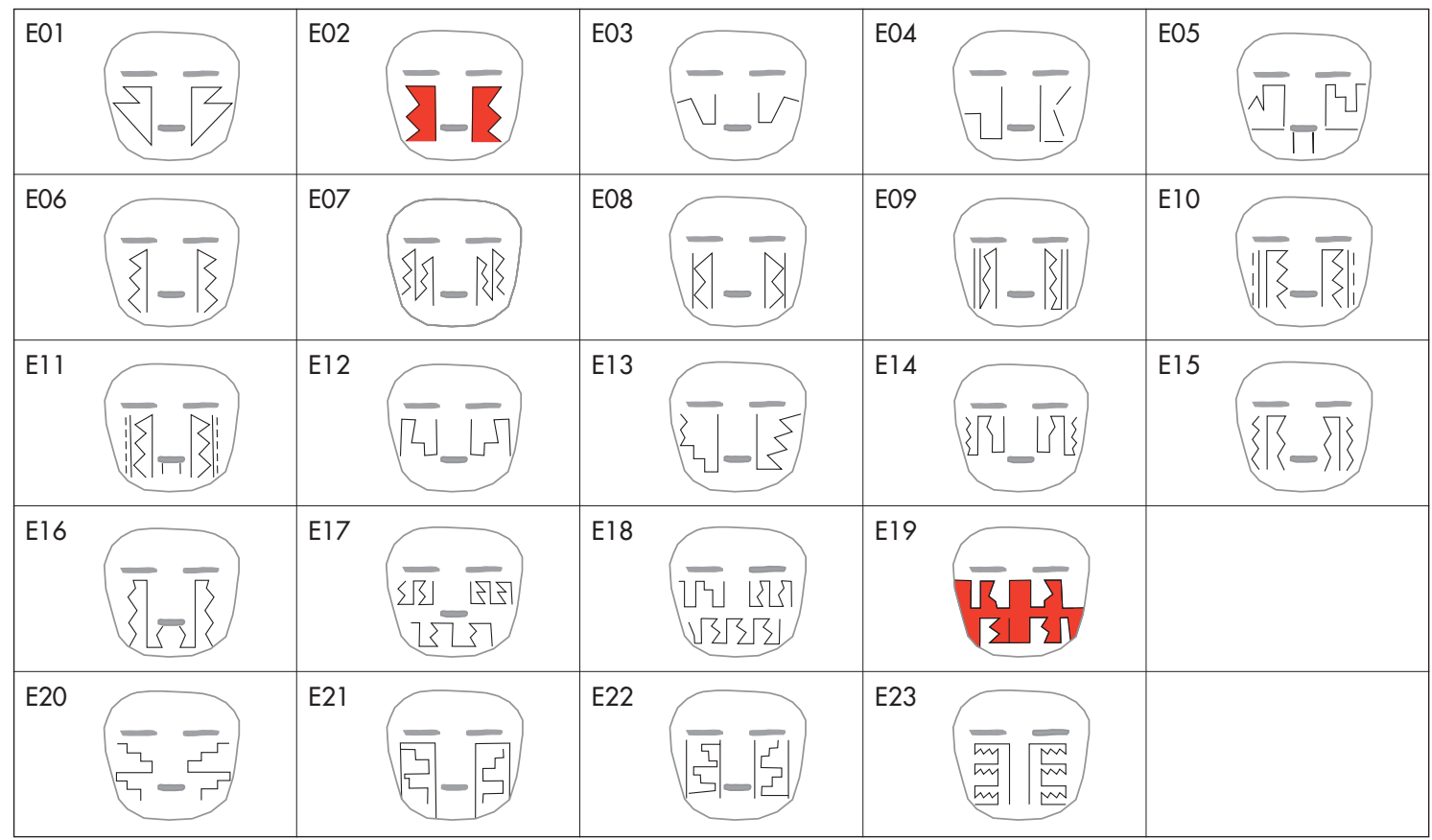

Figura 10. Diseños faciales del grupo E (esfera occidental). Figure 10. Facial designs of group E (western sphere).

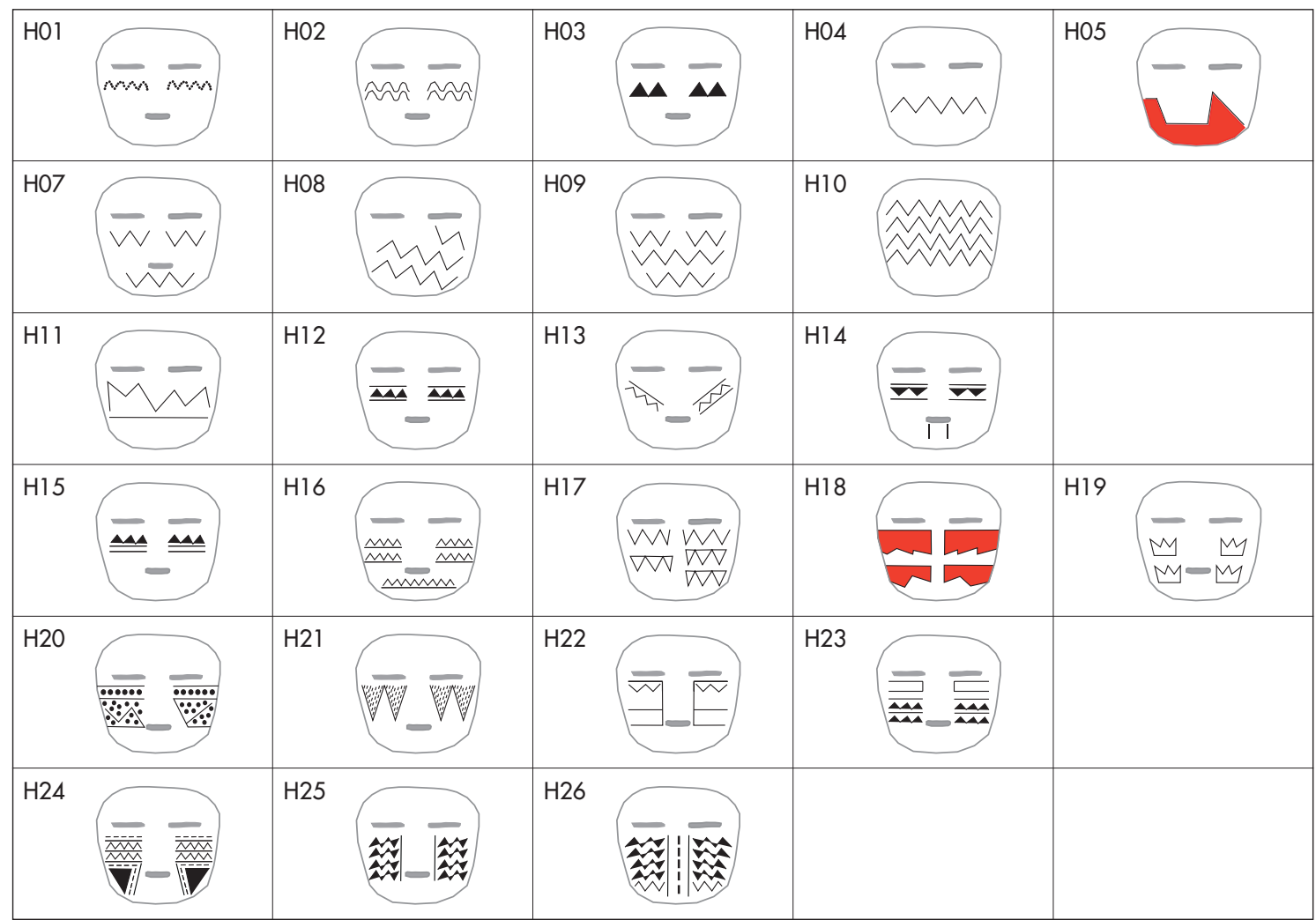

Figura 11. Diseños faciales del grupo H (esfera occidental). Figure 11. Facial designs of group H (western sphere). 


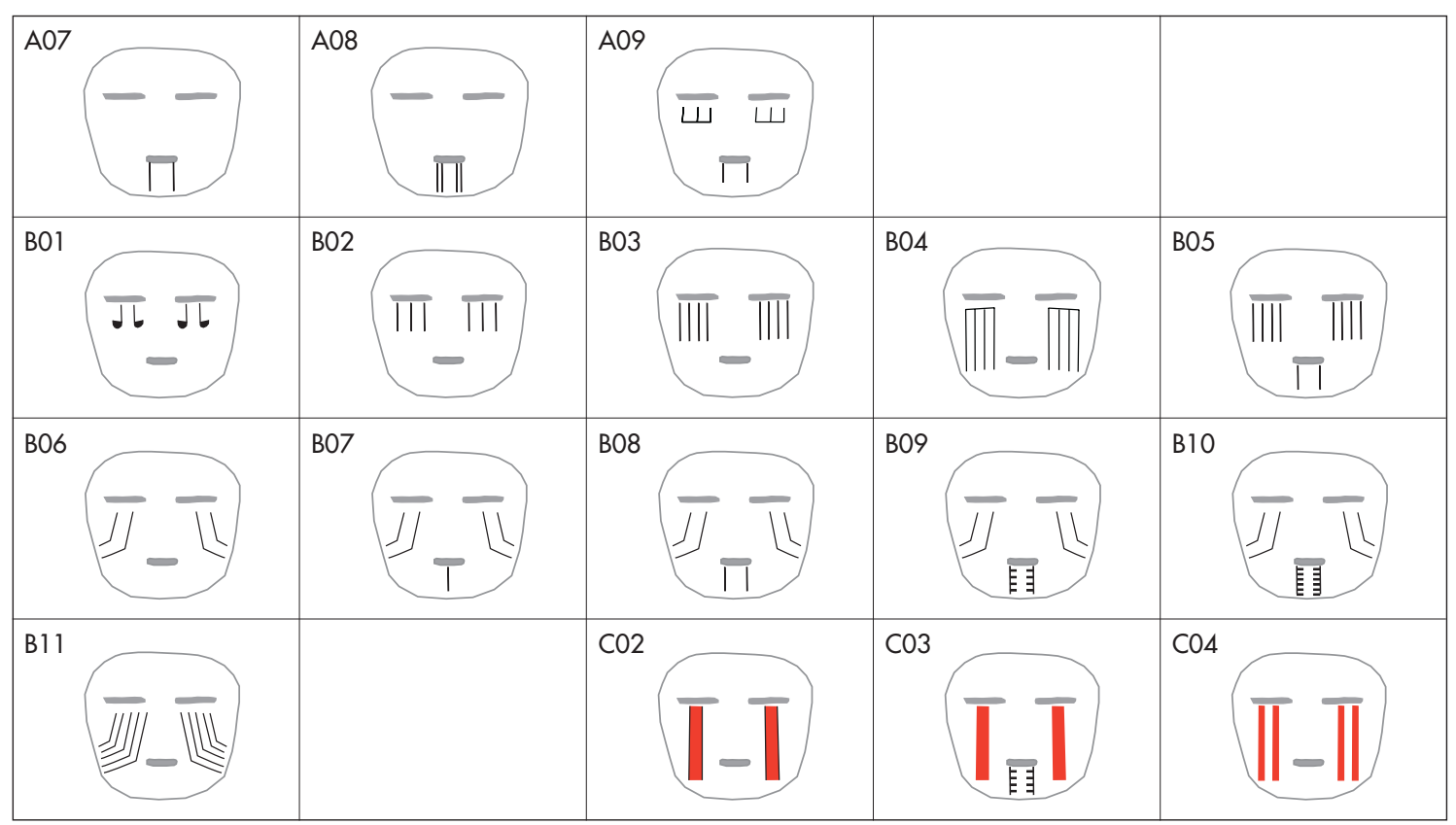

Figura 12. Diseños faciales de los grupos A, B y C (con distribución generalizada). Figure 12. Facial designs of groups A, B and C (with widespread distribution).

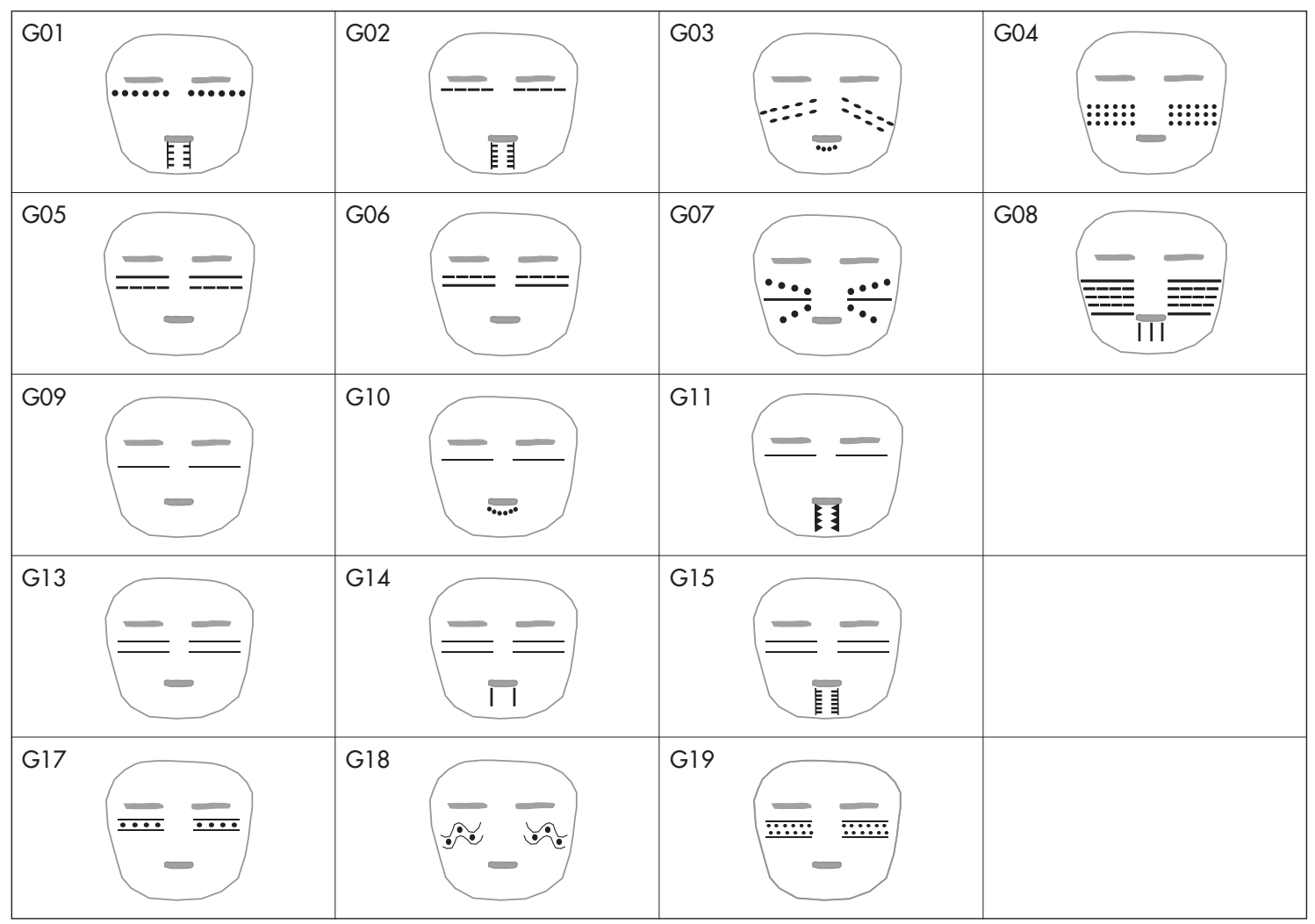

Figura 13. Diseños faciales del grupo G (con distribución generalizada). Figure 13. Facial designs of group G (with widespread distribution). 


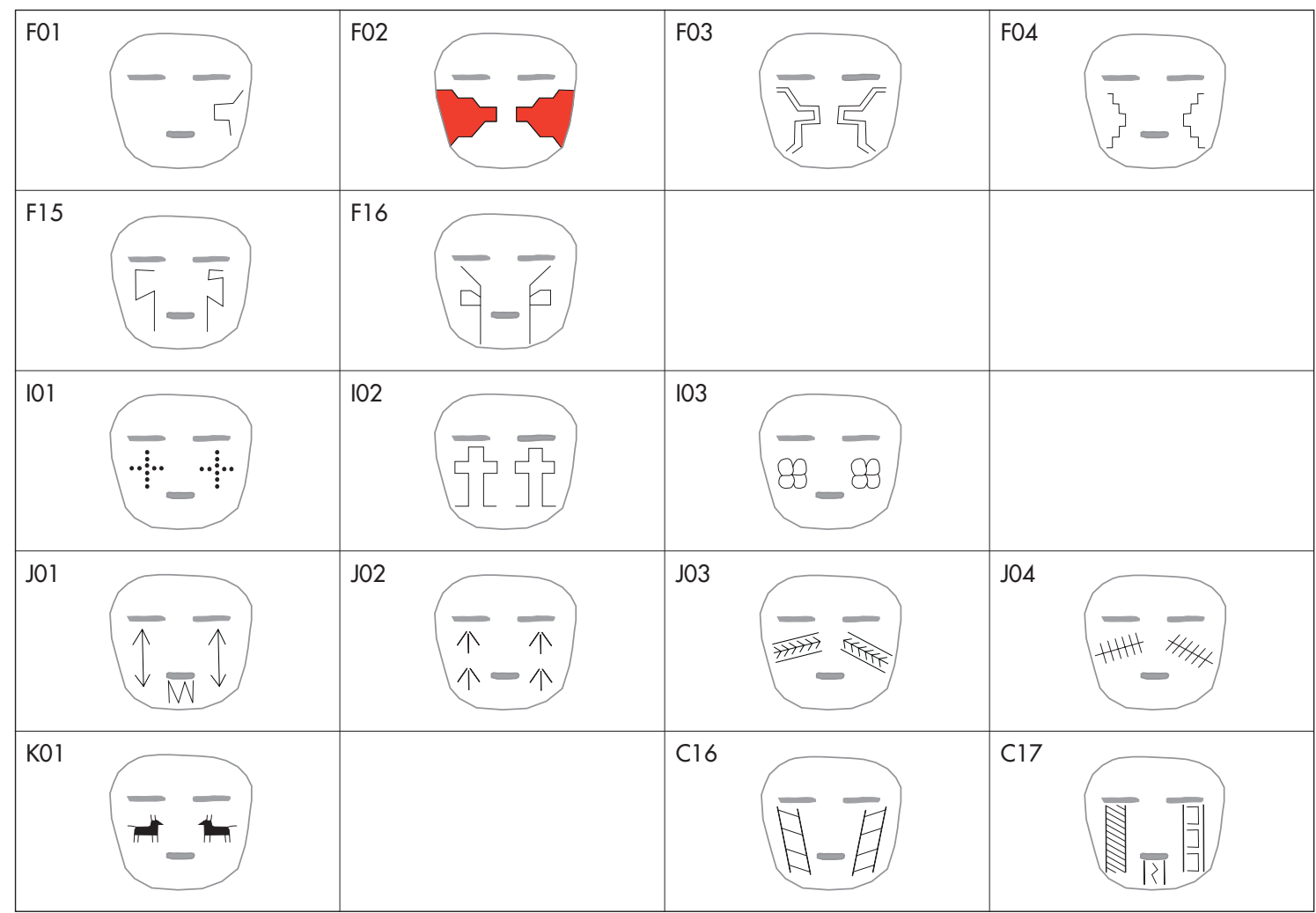

Figura 14. Diseños faciales de los grupos C, F, I, J y K (con distribución puntual). Figure 14. Facial designs of groups C, F, I, J and K (with specific distribution).

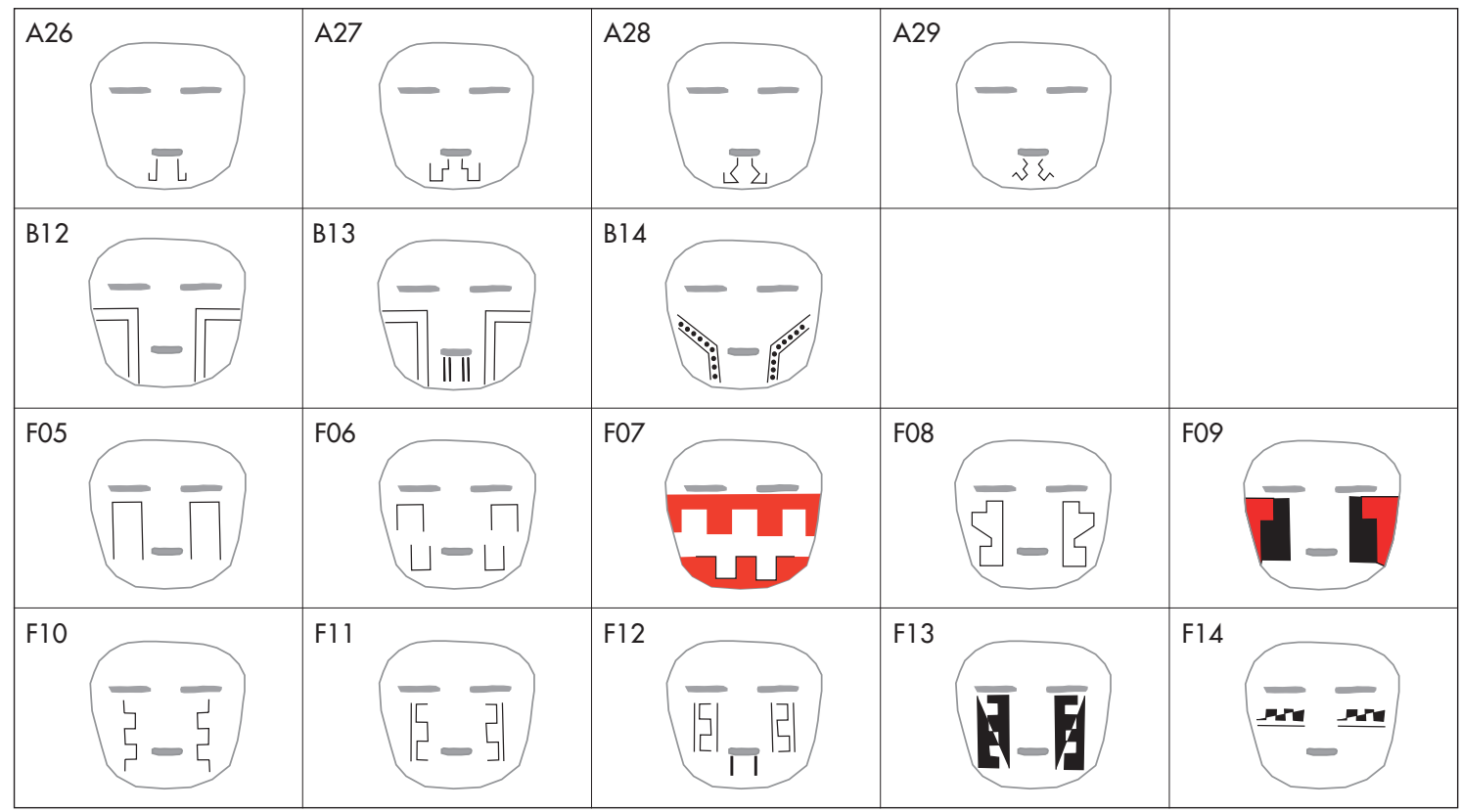

Figura 15. Diseños faciales de los grupos A, B y F (señalan vínculos específicos de PuS con otras áreas). Figure 15. Face designs of groups $A, B$ and $F$ (indicate specific links of $P u S$ with other areas). 


\section{DISCUSIÓN}

Las dos esferas del esquema interpretativo son concebidas como campos sociales relativamente autónomos, construidos a partir de un denso flujo de interacciones internas. En el nivel regional analizado, su carácter reflejaría un aspecto dual, propio de la cosmología y organización de estas antiguas colectividades. Tal condición hipotétitca pudo conectar a los grupos prehispánicos del centro de Argentina con numerosos pueblos originarios de Sudamérica, que comparten o compartieron este tipo de configuración (Cordeu 1989, Zuidema 1991, González 1998, Decoster 2012). Se trataría de un modelo de comprensión del mundo, con una amplia proyección sobre diferentes terrenos y escalas, entre ellos las relaciones intra e intergrupales, así como la producción y circulación de imágenes visuales, incluida la decoración facial de personas y figurinas de arcilla.

A modo de ejemplo, se cita la organización social de los kaingang del sur de Brasil, definida por dos mitades exogámicas, patrilineales, complementarias y asimétricas, designadas como kaméy kainru-kré (Baptista da Silva 2001). Este principio organizativo se refleja en la noción de que todos los seres, objetos y fenómenos naturales se dividen en dos categorías cosmológicas. De este modo su sensibilidad estética, y en consecuencia el sistema de representaciones visuales, también siguen esta pauta ordenadora. Así, los grafismos geométricos de la cestería y de la pintura corporal contrastan y al mismo tiempo, aproximan a los opuestos (Baptista da Silva 2001).

También los chamacoco o ishír del Chaco paraguayo poseían una organización social basada en dos mitades exogámicas (ebytoso y tomaraxo), a su vez subdivididas en clanes que intercambiaban bienes y mujeres. Los clanes o kénaxo estaban segmentados en ocho y, en respuesta al dualismo cosmológico, siete de ellos eran exogámicos y patrilineales, representando la vida, mientras que el octavo era endogámico, en representación de la muerte (Cordeu 1989).

Entre estos grupos la ornamentación tenía en cuenta los ejes de la cosmovisión, centrados en la oposición complementaria entre los ciclos de vida y muerte, respectivamente representados por el rojo y negro. Ambos colores constituían vehículos privilegiados del acontecer de la vida nativa, como metáfora de una sociedad construida sobre un sistema de oposiciones entre segmentos diferentes, manifiesta en diversos campos incluido el estético, expresado en la pintura corporal, las imágenes de dualismos y las asimetrías contrapesadas (Escobar 1993, Cordeu 1999).

De vuelta a la región centro de Argentina, las dos esferas de interacción del esquema interpretativo se definen por el uso excluyente, o casi excluyente, de determinados segmentos del repertorio iconográfico de decoraciones faciales (otros segmentos son ampliamente compartidos entre ambas esferas o, por el contrario, se circunscriben a ámbitos locales internos). Más allá de este aspecto, se advierten diferencias en la lógica de estructuración o funcionamiento de cada una, que eventualmente podrían reflejar su contraposición, complementación y/o asimetría.

La esfera occidental, con epicentro en el área TS, muestra una alta capacidad de generación de formas locales y una alta variabilidad o desregulación de los caudales iconográficos. A través de este medio visual habrían circulado numerosos mensajes, que no obstante eran poco compartidos fuera de los límites de las vecindades inmediatas. En tanto canal comunicativo, la decoración facial, plasmada en figurinas de arcilla, se habría orientado hacia el entramado de relaciones internas, antes que interpelar a sujetos pertenecientes a posiciones o esferas de interacción más alejadas.

Por su parte, la esfera oriental (con epicentro en el área PS-CA) exhibe una limitada capacidad de creación de formas locales, así como una mayor regulación de la variabilidad iconográfica. Comparativamente se habrían transmitido menos mensajes, en base a códigos visuales compartidos entre diferentes grupos. Más allá del entramado de relaciones locales, la decoración facial plasmada en estatuillas de arcilla habría integrado un canal comunicativo parcialmente dirigido hacia "otros", a quienes se buscaba transmitir información no ambigua. Probablemente, según la localización geográfica de esta área, se trataba de una modalidad ajustada a un paisaje de frontera, en parte orientada a la interacción con grupos de las llanuras sudorientales de Córdoba, con quienes existía una mayor distancia cultural (v.g. grupos "pampas", caracterizados por otra lengua, una identidad étnica diferente, etc.).

En este mismo esquema, se destaca la posición y el rol de PuS, ubicada dentro del espacio de interpenetración entre las dos esferas definidas. El repertorio iconográfico desplegado o admitido en esta área comprende las formas distintivas de uno y otro campo, así como imágenes cuya circulación se circunscribe a espacios particulares, con quienes se 
habrían desarrollado vínculos bilaterales específicos. El área PuS y dentro de la misma, puntualmente, la localidad arqueológica San Roque (Outes 1911, Magnín 1937, Furt 1943, Serrano 1945: fig. 1, Pastor et al. 2017), pudo desempeñar un papel especial en la articulación o mediación entre las dos esferas con perfiles en parte excluyentes. Esta orientación pudo estar influenciada, hipotéticamente, por una posición geográfica central entre ambas esferas, a distancia de los entornos que se presumen fronterizos.

\section{CONSIDERACIONES FINALES}

El análisis de los diseños de decoración facial, plasmados en un conjunto de figurinas de arcilla prehispánicas de la región centro de Argentina, aporta expectativas sobre los procesos identitarios y de comunicación visual entre las personas participantes del campo sociocultural en cuestión. Se plantearon hipótesis acerca de la configuración dual que habría definido la cosmología de estas antiguas formaciones sociales, proyectada sobre sus formas de organización y sus creaciones estéticas.

El presente trabajo se define como una aproximación inicial a esta problemática, que deberá complementarse en el futuro con los resultados de otras líneas relacionadas con la comunicación a través de medios visuales. En tal sentido, se espera que el examen de los diseños de camisetas y delantales en las mismas figurinas de arcilla, así como la iconografía plasmada en otros objetos de arte mueble y en sitios con arte rupestre, permita precisar aspectos de las redes de interacción, la circulación de información y la creación de identidades personales y colectivas.

Agradecimientos a Inés Gordillo y Mara Basile, por sus aportes durante el simposio "De la imagen a los contextos. Sobre las maneras de abordar e interpretar la producción visual en Arqueología”, celebrado en el marco del xix Congreso Nacional de Arqueología Argentina, así como durante la preparación de la presente compilación. A los responsables de los museos de arqueología y colecciones consultadas: Carlos Carmona, Alberto Cubría, Sergio Dell'Orsi, Arturo Ferraretto, Pedro Flores, Alejandra Funes, Silvana González, Rodolfo Herrero, Andrea Kranewitter, Silvia Ledda, Nelso Lenarduzzi, Dora de Loza y Sebastián Vecchio. La investigación fue financiada con fondos del CONICET.

\section{REFERENCIAS}

Allison, M., Focacci, G., Arriaza, B., Standen, V., RIVera, M. \& Lowenstein, J. 1984. Chinchorro, momias de preparación complicada: métodos de momificación. Chungara 13: 155-173.

ArriazA, B. 1988. Modelo bioarqueológico para la búsqueda y acercamiento a individuo social. Chungara 21: 9-32.

BAPTiSTA DA SiLVA, S. 2001 Ms. Etnoarqueologia dos grafismos Kaingang: um modelo para a compreensão das sociedades Proto-Jê meridionais. Tesis para optar al grado de Doctor, Universidad de San Pablo, San Pablo, Brasil.

Berberián, E. 1984. Potrero de Garay: una entidad sociocultural tardía de la región serrana de la provincia de Córdoba. Comechingonia 4: 71-138.

Berberián, E. 1987. Crónicas del Tucumán. Siglo Xvi. Córdoba: Comechingonia.

Bonofiglio, M. 1985. Un conjunto de estatuillas antropomorfas de los yacimientos de Río Segundo, Provincia de Córdoba, República Argentina. Centro de Estudios de Regiones Secas III (1-2).

Cichero, A. 2016. Tattooing in Moche culture: reconsidering the identity of the Lady of Cao. The Ancient World Online: 1-18.

CifARELli, M. \& GALINSKI, L. 2017. What shall I say of clothes? Theoretical and methodological approaches to the study of dress in antiquity. Boston: Archaeological Institute of America.

Colazo, S. 1970. Las "muñecas" del Chaco. Runa 12 (1-2): 413-425.

Cordeu, E. 1989. Chamacoco o Ishir del Chaco boreal: algunos aspectos de un proceso de desestructuración étnica. América Indígena 49 (3): 545-580.

Cordeu, E. 1999. Transfiguraciones simbólicas. Ciclo ritual de los indios tomaráxo del Chaco boreal. Quito: Abya-Yala.

Cornely, F. 1947-1949. Cultura diaguita-chilena (Provincia de Coquimbo y Atacama). Revista Chilena de Historia Natural 51-53: 119-262.

Croucher, K. 2010. Figuring out identity: the body and identity in the Ubaid. En Beyond the Ubaid. Transformation and integration in the late prehistoric societies of the Middle East, R. Carter \& G. Philip, Eds., pp. 113-123. Chicago: The Oriental Institute of The University of Chicago.

Decoster, J. 2012. La dualidad andina revisitada: en torno a las operaciones de las formas sociales en contextos rituales. En Cultura andina: cosmovisión, arqueología, W. Rozas \& D. Valencia, Eds., pp. 269-281. Cuzco: CCss-UnsaAC.

Escobar, T. 1993. La belleza de los otros. Asunción: RP Ediciones.

Franco, R. 2008. La señora de Cao. En Señores de los Reinos de la Luna, K. Makowski, Ed., pp. 280-287. Lima: Banco de Crédito del Perú.

FurT, J. 1943. Escultura indígena de Córdoba. Actas del Congreso de Historia Argentina del Norte y Centro I: 121-129. 
GonzÁlez, A. 1943. Figuras antropomorfas de los paraderos indígenas de Córdoba. Actas del Congreso de Historia Argentina del Norte y Centro I : 159-180.

González, A. 1998. Arte precolombino. Cultura La Aguada. Arqueología y diseños. Buenos Aires: Filmediciones Valero.

Hansen, K. 2004. The world in dress: anthropological perspectives on clothing, fashion, and culture. Annual Review of Anthropology 33: 369-392.

IDoyaGA, I. 2000. Cuerpo e identidad étnica y social. Un análisis de las representaciones Pilagá. Boletín Antropológico 49: 29-52.

Imbelloni, J. 1950. La extraña terracota de Rurrenabaque (Noreste de Bolivia) en la arqueología de Sudamérica. Runa 3: 71-169.

IRIBARREN, J. 1969. Culturas precolombinas en el norte medio precerámico y formativo. Boletín del Museo Nacional de Historia Natural 30: 147-208.

MAGNín, J. 1937. El vestido y el adorno en las figuras iconográficas indianas de San Roque (Punilla, Córdoba). Revista de la Universidad Nacional de Córdoba XXIV (1-2): 130-170.

Marcellino, A., Berberián, E. \& Pérez, J. 1967. El yacimiento arqueológico de Los Molinos (Dpto. Calamuchita, Córdoba). Publicaciones del Instituto de Antropología Xxvi.

MARTín, V. 1983. Representaciones plásticas antropomorfas del yacimiento "Potrero de Garay" (Dto. Santa María, Pcia. de Córdoba). Comechingonia 3: 49-60.

Medina, M., Pastor, S. \& Berberián, E. 2014. "Es gente fazil de moverse de una parte a otra". Diversidad en las estrategias de subsistencia y movilidad prehispánicas tardías (Sierras de Córdoba, Argentina). Complutum 25 (1): 73-88.

Métraux, A. 1942. The native tribes of Eastern Bolivia and Western Matto Grosso. Washington: Smithsonian Institution.

Miguez, G. E., Caria, M. \& Pantorrilla, M. 2014. Las estatuillas cerámicas en la vida de las poblaciones prehispánicas de las selvas subtropicales meridionales del Noroeste Argentino. Revista Española de Antropología Americana 44 (1): 39-63.

Orquera, L. \& Piana, E. 1999. La vida material y social de los yámana. Buenos Aires: Eudeba.

Outes, F. 1911. Los tiempos prehistóricos y protohistóricos en la provincia de Córdoba. Revista del Museo de La Plata XVII: 261-374.

Pastor, S. \& Tissera, L. 2015. Géneros rituales: figuras sexuadas en cerámica y arte rupestre de las Sierras de Córdoba. Cuadernos del Instituto Nacional de Antropología y Pensamiento Latinoamericano 24 (2): 63-86.

Pastor, S., Medina, M., Recalde, A., López, L. \& Berberián, E. 2012. Arqueología de la región montañosa central de Argentina. Avances en el conocimiento de la historia prehispánica tardía. Relaciones de la Sociedad Argentina de Antropología xxxviI (1): 89-112.

Pastor, S., Gordillo, S. \& Tissera, L. 2017. Objetos y paisajes multisensoriales del Holoceno Tardío Inicial en el centro de Argentina (ca. 3900 años AP). Acerca de un contexto arqueomalacológico de las Sierras de Córdoba. Intersecciones en Antropología 18: 317-327.

Paucke, F. 2010 [1769]. Hacia allá y para acá (memorias). Santa Fe: Ministerio de Innovación y Cultura de la Provincia de Santa Fe.

Proulx, D. 1999. The Nasca culture: an introduction. En Nasca: geheimnisvolle Zeichen im Alten Peru, J. Rickenbach, Ed., pp. 59-77. Zürich: Museum Rietberg Zürich.

Quetzal 2010. La estatuaria comechingona. Rostros del pasado. Córdoba: Camiares.

Rusconi, C. 1961. Poblaciones pre y posthispánicas de Mendoza. Volumen I Etnografía. Mendoza: Edición oficial.

Serrano, A. 1944. Las estatuillas de arcilla de Córdoba y su significado arqueológico. Publicaciones del Instituto de Arqueología, Lingüística y Folklore "Dr. Pablo Cabrera" viI.

Serrano, A. 1945. Los comechingones. Córdoba: Instituto de Arqueología, Lingüística y Folklore "Dr. Pablo Cabrera", Universidad Nacional de Córdoba.

Ubbelohde-Doering, H. 1967. On the royal highways of the Incas: archaeological treasures of ancient Peru. Nueva York: Frederick Praeger.

Vanpool, C., Vanpool, T. \& Downs, L. 2017. Dressing the person: clothing and identity in the Casas Grandes world. American Antiquity 82 (2): 262-287.

Wyler-Castellanos, B. 1924. Manifestaciones coroplásticas en el valle de Los Reartes (Prov. de Córdoba). Revista de la Universidad Nacional de Córdoba XI (7-8-9): 139-149.

Zuidema, T. 1991. La civilización Inca en Cuzco. México: Fondo de Cultura Económica. 